\title{
Experiments on a Modular Magnetic Refrigeration Device
}

\author{
Kurt Engelbrecht* - Jesper Buch Jensen - Christian Robert Haffenden Bahl \\ Fuel Cells and Solid State Chemistry Division, Risø National Laboratory for Sustainable Energy, \\ Technical University of Denmark, Denmark
}

An experimental magnetic refrigeration test device has been built at Risø DTU. The device is designed to be modular, and thus all parts of the device can easily be replaced depending on the experiment. This makes the device highly versatile, with the possibility of performing a wide variety of different experiments. The test device is of the reciprocating type, and the magnetic field source is provided by a permanent Halbach magnet assembly with an average flux density of 1.03 Tesla. This work presents experimental results for flat plate regenerators made of gadolinium and sintered compounds of $\mathrm{La}(\mathrm{Fe}, \mathrm{Co}, \mathrm{Si})_{13}$ and experimentally investigates the effect of thermal conduction through the regenerator housing walls. Each regenerator was tested over a range of hot reservoir temperatures under no load conditions for a regenerator comprised of gadolinium. The test machine was also tested with two different compositions of $\mathrm{La}(\mathrm{Fe}, \mathrm{Co}, \mathrm{Si})_{13}$ compounds. Test results are presented for a regenerator made of a single $\mathrm{La}(\mathrm{Fe}, \mathrm{Co}, \mathrm{Si})_{13}$ material and a two-material regenerator, and the results are compared to the same system using gadolinium.

(C2011 Journal of Mechanical Engineering. All rights reserved.

Keywords: experiment, magnetic refrigeration, gadolinium, regenerator

\section{INTRODUCTION}

Active magnetic regenerative (AMR) refrigerators are a potentially environmentallyfriendly alternative to vapor compression technology that could potentially be used for air-conditioning, refrigeration, and heat pump applications. Rather than using a gaseous refrigerant, AMRs use magnetocaloric materials (MCMs) that have a coupling between their thermodynamic properties and internal magnetic field. The magnetization of an MCM is analogous to the compression of a gas in that the material's state becomes more ordered. With magnetization, the material's entropy is lowered, and the temperature increases if conditions are adiabatic. AMRs are still a developing technology and there is much research effort currently focused on improving AMR performance through the development of new MCMs and system designs. Gadolinium has been the most commonly used MCM in recent AMR machines [1], but many new materials are being developed and characterized [2]. One MCM with the potential to improve system performance over $\mathrm{Gd}$ is the $\mathrm{La}(\mathrm{Fe}, \mathrm{Co}, \mathrm{Si}) 13$ series of materials. This work compares the two materials in a prototype AMR.
A single regenerator reciprocating AMR test machine has been built and used to test different magnetocaloric materials and regenerator designs. The volume of the regenerator, not including housing and external hardware, is approximately $15 \mathrm{~cm}^{3}$, and the magnetic field is provided by a Halbach cylinder type permanent magnet with an average flux density in the bore of $1.03 \mathrm{~T}$. The magnet, which is described by [3], has a bore of $42 \mathrm{~mm}$ and a height of $50 \mathrm{~mm}$. Magnetization and demagnetization of the regenerator are achieved by moving the regenerator vertically relative to the stationary magnet by use of a stepper motor. The test device is described in detail by [4] and was designed so that the regenerator housing can be easily changed, allowing a range of regenerator designs to be tested quickly. However, only flat plate regenerators have been tested up to this point. In order to test the machine's performance over a range of operating temperatures and to better control the experimental conditions, the device was placed in a temperature controlled cabinet with the hot reservoir in thermal contact with the air in cabinet. In this work, the air inside the temperature controlled cabinet is considered ambient. This paper presents no-load temperature span measurements for a test machine using a flat

*Corr. Author's Address: Risø DTU,

Frederiksborg 399, 4000 Roskilde, Denmark, kuen@risoe.dtu.dk 
plate gadolinium regenerator and a regenerator made of plates of two sintered $\mathrm{La}(\mathrm{Fe}, \mathrm{Co}, \mathrm{Si})_{13}$ materials.

A simple schematic of the test machine is given in Fig. 1. The regenerator has a Perspex tube screwed onto each end, with the hot reservoir located in the tube above the regenerator and the cold reservoir in the tube below. There is a resistance heater installed in the regenerator's cold reservoir to simulate a cooling load. Heat transfer fluid is moved through the regenerator by means of a displacer in the cold reservoir.

The entire device is placed in contact with the same ambient temperature; however, the hot reservoir is thermally linked to ambient via a forced convection heat exchanger while the cold reservoir is insulated from ambient using foam tubing. All thermal losses through the regenerator housing and cold reservoir will go to the ambient temperature. This test machine was used to measure the no-load temperature span of a flat plate regenerator for a range of operating conditions using regenerators made of gadolinium and one and two-material regenerators made of $\mathrm{La}(\mathrm{Fe}, \mathrm{Co}, \mathrm{Si})_{13}$ and the results are presented below.

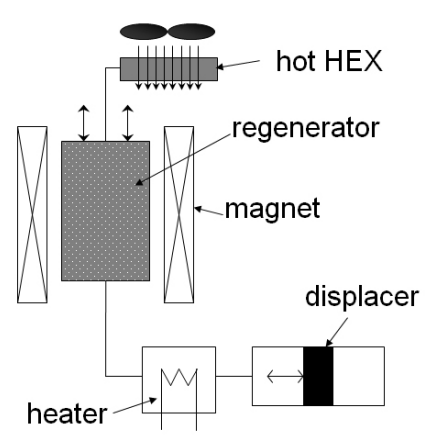

Fig. 1. Schematic of the test machine

\section{THE REGENERATOR HOUSING}

The goal of the test machine described here is to test a range of AMR designs quickly when subjected to consistent conditions. The regenerators were fabricated using rapid prototyping techniques. Rapid prototyping was chosen because a range of detailed geometries can be produced in a single piece, eliminating fluid leakage. Some types of rapid prototyping processes use plastics with relatively low thermal diffusivities, such as acrylic or nylon, which should reduce interactions between the heat transfer fluid and regenerator housing. The regenerator is $40 \mathrm{~mm}$ in the direction of flow with a rectangular flow opening $23 \mathrm{~mm}$ wide by $17 \mathrm{~mm}$ high. Each plate is held in place by a $1 \mathrm{~mm}$ tall slot that runs the entire length of the regenerator. Plate spacing is controlled by ribs between each slot, and the height of each rib can be no less than $0.5 \mathrm{~mm}$ due to manufacturing limitations. The regenerator houses 11 plates with the top and bottom plates in direct contact with the housing to reduce interactions between the heat transfer fluid and regenerator housing. The heat transfer fluid is a mixture of $75 \%$ water and $25 \%$ automotive antifreeze. Consumer antifreeze, which is based on ethylene glycol, was chosen over laboratory grade ethylene glycol because it has corrosion inhibitors that reduce the corrosion of several of the magnetocaloric materials under consideration in this paper.

This paper shows results for $0.9 \mathrm{~mm}$ thick commercial grade Gd plates held in place in two different regenerator housings. The first is made using a PolyJet process, where droplets of an acrylic-based polymer are deposited in layers with a thickness of approximately $0.02 \mathrm{~mm}$ and hardened after each deposition. The second is made using a selective laser sintering (SLS) process, where layers of nylon powder $0.1 \mathrm{~mm}$ in thickness are selectively sintered to form the final part. The SLS process was chosen because it could be used to produce a regenerator housing with hollow walls, which should reduce thermal conduction to the ambient. The PolyJet process could not be used to make the hollow-walled regenerator housing because the process uses a wax support structure that would be difficult to remove from the space inside the walls. A CAD cross-section of the hollow regenerator is shown in Fig. 2. As shown in the figure, there must still be a support structure for the regenerator plates, but the overall conduction path is reduced by using a hollow wall. Assuming that the hollow volume is filled with quiescent air, the thermal resistance through the hollow housing and solid housing can be estimated. Using an average distance occupied by the air, the thermal resistance through the hollow 
regenerator wall is approximately 4 times greater than through the solid regenerator housing. The minimum wall thickness is $2.2 \mathrm{~mm}$ for the hollow regenerator housing. The PolyJet regenerator has the same geometry as the one shown in Fig. 2, with the exception that the wall between the opening for the regenerator plates and the outside is solid.

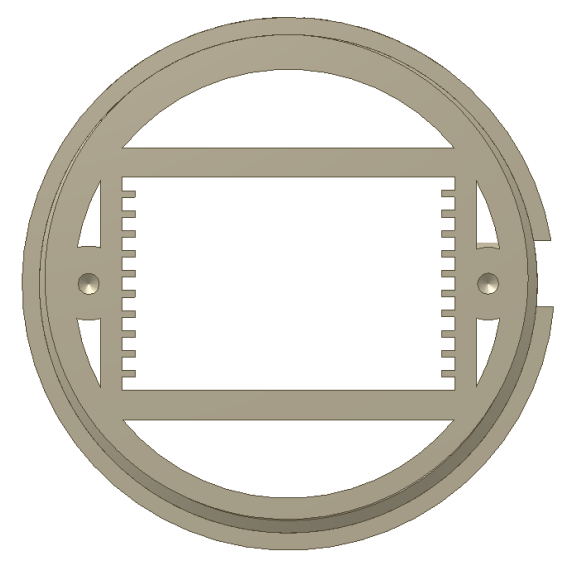

Fig. 2. CAD drawing of a regenerator with hollow walls made with SLS

\section{EXPERIMENTAL RESULTS}

\subsection{Flat Plate Gadolinium Regenerator}

The solid and hollow regenerators were tested over a range of ambient temperature to determine the optimum temperature span of the test device. Both regenerators were tested with $0.9 \mathrm{~mm}$ thick commercial grade gadolinium plates with a spacing of $0.5 \mathrm{~mm}$. In order to determine operating parameters that are near optimal, the solid PolyJet regenerator was used for a range of experiments where the fluid flow rates and cycle times were varied. Operating conditions that result in the optimal no-load temperature span were determined experimentally and they are shown in Table 1. The AMR cycle is broken into four separate processes for the test machine presented here. The cold-to-hot blow starts only when the regenerator is fully magnetized, and the hot-tocold blow starts after the regenerator is moved fully out of the magnetic field. Therefore, if the time for any single process is changed, the cycle time is also changed.
Table 1. Operating conditions for ambient temperature variation experiment using the commercial grade gadolinium flat plate regenerator

\begin{tabular}{|l|c|}
\hline \multicolumn{1}{|c|}{ Parameter } & Value \\
\hline Fluid velocity & $8.2 \mathrm{~mm} / \mathrm{s}$ \\
\hline Cycle time & $8 \mathrm{~s}$ \\
\hline Utilization & 0.55 \\
\hline
\end{tabular}

The regenerator utilization, $U$, is defined as

$$
U=\frac{v_{f} A_{f} \tau_{2} \rho_{f} c_{f}}{V_{S} \rho_{S} c_{c}},
$$

where $\tau_{2}$ is the time for a blow period, $v_{f}$ is the fluid velocity, $A_{f}$ is the cross-sectional area available for fluid flow, $\rho_{f}$ and $\rho_{s}$ are the fluid and solid densities, respectively, $c_{f}$ and $c_{s}$ are the specific heats of the fluid and solid, respectively, and $V_{S}$ is the volume of the solid regenerator material. The average specific heat of gadolinium is assumed to be $260 \mathrm{~J} /(\mathrm{kgK})$ based on data from [6].

The ambient temperature was varied in a range around the Curie temperature of $\mathrm{Gd}$ $\left(21{ }^{\circ} \mathrm{C}\right)$ and the no-load temperature span was measured for the solid and hollow regenerators. The results are shown in Fig. 3. The hot heat exchanger generally maintains the hot reservoir to approximately $1{ }^{\circ} \mathrm{C}$ or less above ambient temperature.

Fig. 3 shows that the maximum temperature span is achieved at an ambient temperature of approximately $25{ }^{\circ} \mathrm{C}$ for both regenerators. It has previously been reported that the optimum hot-end temperature is just above the Curie temperature [7]. At an ambient temperature of $24{ }^{\circ} \mathrm{C}$, the regenerator operates approximately between 16 and $25^{\circ} \mathrm{C}$. The Curie temperature is close to the middle of this range, meaning that the entropy change with magnetization of the material is maximized. The hollow regenerator housing generally performs slightly better than the solid housing, but the difference is near the experimental uncertainty for the device which is estimated at approximately $0.2{ }^{\circ} \mathrm{C}$. As the temperature span of the device increases, the performance of the hollow housing may improve relative to the solid housing. However, for a temperature span below $10{ }^{\circ} \mathrm{C}$, the benefit of the hollow regenerator housing is relatively small. 
The effect of ambient temperature relative to the hot and cold reservoirs was also tested. The device was run at the same operating conditions but with a reduced pump speed in the hot heat exchanger, and the resulting temperature span was measured. With the hot heat exchanger effectiveness reduced, the ambient temperature was set to $22.5{ }^{\circ} \mathrm{C}$ and the regenerator produced a no-load span of $10.2{ }^{\circ} \mathrm{C}$ between 15.6 and $25.8^{\circ} \mathrm{C}$. The temperature span that was achieved when the hot reservoir was allowed to rise more than $3{ }^{\circ} \mathrm{C}$ above ambient increased the device's temperature span by more than $1^{\circ} \mathrm{C}$. This could be due to the reduced temperature difference between the cold reservoir and ambient or the reduced temperature difference between any location along the regenerator and ambient. Because the losses through the regenerator wall were shown to be relatively small, it is possible that there is a thermal leak from the cold reservoir to the ambient that causes a noticeable reduction in performance.

\subsection{Experimental Results for a Two-Material Regenerator}

Plates of $0.9 \mathrm{~mm}$ thickness have been provided by a commercial supplier of two compositions of sintered $\mathrm{La}(\mathrm{Fe}, \mathrm{Co}, \mathrm{Si})_{13}$ with Curie temperatures of approximately 3 and $16{ }^{\circ} \mathrm{C}$. The properties of the $T_{C}=3{ }^{\circ} \mathrm{C}$ material tested here are given by [8]. $\mathrm{La}(\mathrm{Fe}, \mathrm{Co}, \mathrm{Si})_{13}$ materials are attractive materials for AMR systems because they have a higher entropy change with magnetization than gadolinium, although they exhibit a smaller adiabatic temperature change upon magnetization. Each plate is $0.9 \mathrm{~mm}$ thick and $20 \mathrm{~mm}$ long or half the length of the gadolinium plates discussed above. The layered bed is constructed by simply butting two plates of different materials together. The solid regenerator housing was run with a regenerator made of only the $T_{C}=16{ }^{\circ} \mathrm{C}$ material and the system reached a no load temperature span of $7.9^{\circ} \mathrm{C}$, with the regenerator operating between 10.1 and $18.0^{\circ} \mathrm{C}$ while the ambient temperature was set to $15.6^{\circ} \mathrm{C}$.

The layered bed was tested at an ambient temperature of $13{ }^{\circ} \mathrm{C}$ for a range of utilizations and heat transfer fluid velocities, and the no-load temperature span was measured. The cycle time is a function mostly of fluid velocity and utilization. Thus, for the same utilization, the cycle time will be longer for a lower fluid velocity. Testing of the layered $\mathrm{La}(\mathrm{Fe}, \mathrm{Co}, \mathrm{Si})_{13}$ showed that the system was most sensitive to fluid velocity, with cycle time and utilization having relatively small effects on system performance for conditions tested here. The experimental results are shown in Fig. 4. The dependence on fluid velocity may be due to the increased time for heat transfer between the fluid and solid when the velocity is lower. Changing the ambient temperature for this experiment does not significantly affect the results, provided

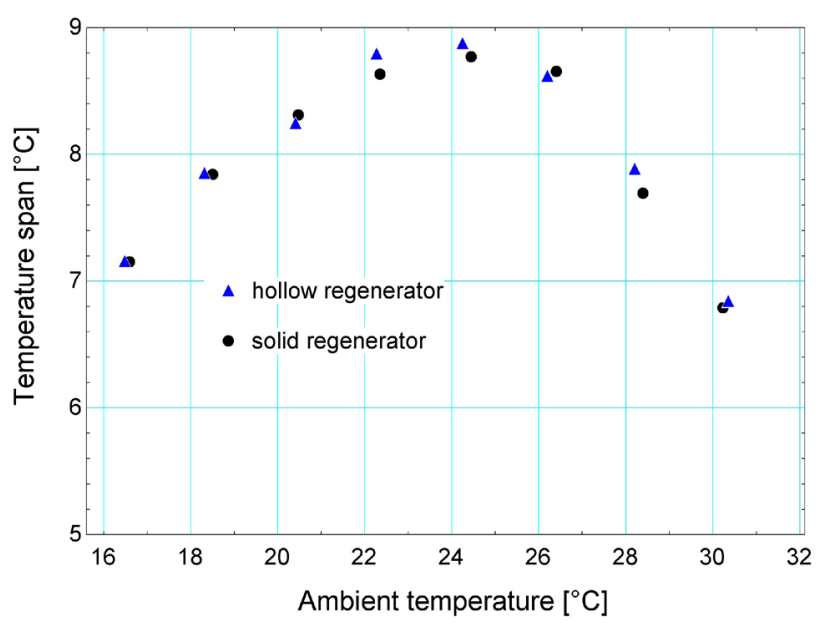

Fig. 3. No-load temperature span as a function of ambient temperature for the operating conditions shown in Table 1 


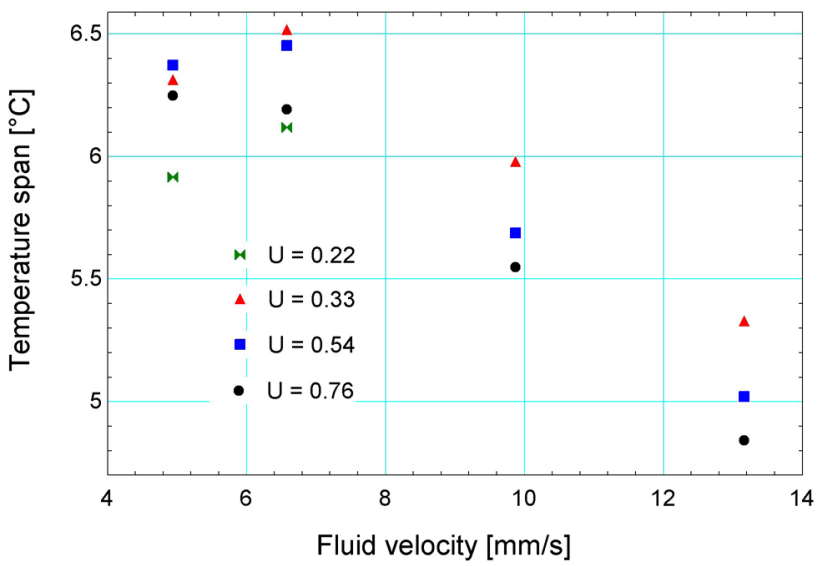

Fig. 4. No load temperature span as a function of fluid velocity for a two-material $\mathrm{La}(\mathrm{Fe}, \mathrm{Co}, \mathrm{Si})_{13}$ regenerator

it lies between the Curie temperatures of the two materials. Theinsensitivity to operating temperature may be due to the fact that the difference between the Curie temperatures of the two materials is higher than the temperature span that can be achieved by this regenerator design.

Examination of Fig. 4 shows that the no-load temperature span is similar for a range of utilizations when the fluid velocity is held constant. However, the results are dependent on fluid velocity, achieving the largest temperature span with a fluid velocity of $6.6 \mathrm{~mm} / \mathrm{s}$. The system showed very little dependence on cycle time. For example, the case with a utilization of 0.33 and fluid velocity of $6.6 \mathrm{~mm} / \mathrm{s}$ has a cycle time of $9.2 \mathrm{~s}$ while the experiment with a utilization of 0.76 and the same fluid velocity had a cycle time of $17 \mathrm{~s}$, but the temperature span showed a difference of only $0.3{ }^{\circ} \mathrm{C}$. There is a much more drastic change in performance as the fluid velocity is changed. The maximum temperature span for the layered regenerator is $6.5^{\circ} \mathrm{C}$, which is $1.5^{\circ} \mathrm{C}$ lower than the temperature span for a single material $\mathrm{La}(\mathrm{Fe}, \mathrm{Co}, \mathrm{Si})_{13}$ regenerator. The layered regenerator probably did not perform as well as the single material bed because the Curie temperatures of the magnetocaloric materials are too far apart for this regenerator design. As the regenerator cannot produce a large enough temperature span to reach the temperature where the low-Curietemperature material has high magnetocaloric performance, the potentially higher temperature span for the layered regenerator was not realized.
During the operation of the test machine, the $\mathrm{La}(\mathrm{Fe}, \mathrm{Co}, \mathrm{Si})_{13}$ plates were more prone to break than the gadolinium plates that were also tested. It is not clear if the plates were broken during assembly/disassembly or during operation, but brittleness should be a concern when designing a system using $\mathrm{La}(\mathrm{Fe}, \mathrm{Co}, \mathrm{Si})_{13}$ materials.

\section{CONCLUSIONS}

No-load temperature spans have been presented for two different regenerator designs and two different regenerator materials. By testing a regenerator with hollow walls, it was shown that thermal losses through the regenerator wall to ambient do not significantly affect the test machine's performance when the temperature span is less than $10^{\circ} \mathrm{C}$. However, as the temperature span increases, losses through the regenerator wall will also increase and reducing the conduction through the regenerator housing may have a larger impact on performance. Tests presented in this paper show that a single-material AMR performs best when the Curie temperature is within the working temperature span of the machine. The test machine presented is able to control the operating temperature of the AMR and therefore is able to test a given $\mathrm{MCM}$ in its optimum temperature range and provide a meaningful comparison between potential new working materials with different Curie temperatures.

Single-material and layered bed regenerators were made from $\mathrm{La}(\mathrm{Fe}, \mathrm{Co}, \mathrm{Si})_{13}$ 
compounds, and the no load temperature span was found to be lower than that of gadolinium when both materials operated near their respective Curie temperatures. Also, the layered regenerator provided a lower temperature span than the single material regenerator because the two materials had Curie temperatures that were too far apart for the regenerator design that was tested. However, $\mathrm{La}(\mathrm{Fe}, \mathrm{Co}, \mathrm{Si})_{13}$ compounds exhibit relatively high entropy change with magnetization and still hold promise for AMR systems provided the materials are chosen correctly.

\section{ACKNOWLEDGEMENTS}

We thank Mr. Jørgen Geyti for his technical help. Also, we thank Vacuumschmelze GmbH \& Co. KG, 63450 Hanau, Germany for supplying the plates of $\mathrm{La}(\mathrm{Fe}, \mathrm{Co}, \mathrm{Si})_{13}$. The authors further acknowledge the support of the Programme Commission on Energy and Environment (EnMi) (Contract No. 2104-06-0032), which is part of the Danish Council for Strategic Research.

\section{REFERENCES}

[1] Gschneidner Jr.K.A., Pecharsky, V.K., Tsokol, A.O. (2005). Recent developments in magnetocaloric materials. Reports On Progress In Physics, vol. 68, p. 1479-1539, DOI:10.1088/0034-4885/68/6/R04.

[2] Engelbrecht, K.L., Nellis, G.F., Klein, S.A., Zimm, C.B. (2007). Recent developments in room temperature active magnetic regenerative refrigeration. $\quad H V A C \& R$ Research, vol. 13, p. 525-542.

[3] Bjørk, R., Bahl, C.R.H., Smith, A., Pryds, N. (2010). Review and comparison of magnet designs for magnetic refrigeration. International Journal of Refrigeration, vol. 33, p. 437-448, DOI:10.1016/j. ijrefrig.2009.12.012.

[4] Bahl, C.R.H., Petersen, T.F., Pryds, N., Smith, A. (2008). A versatile magnetic refrigeration test device. Review of Scientific Instruments, vol. 79, Article no. 093906, DOI:10.1063/1.2981692.

[5] Dragutinovic, G.D., Baclic, B.S. (1998). Operation of counterflow regenerators. Computational Mechanics Inc., Billerca.

[6] Dan'kov, S.Y., Tishin, A.M., Pecharsky, V.K., Gschneidner, K.A. (1998). Magnetic phase transitions and the magnetothermal properties of gadolinium. Physical Review B, vol. 57, no. 6, p. 3478-3490, DOI:10.1103/ PhysRevB.57.3478.

[7] Rowe, A., Tura, A. (2008). Active magnetic regenerator performance enhancement using passive magnetic materials. Journal of Magnetism and Magnetic Materials, vol. 320, p. 1357-1363, DOI:10.1016/j. jmmm.2007.11.018.

[8] Hansen, B.R., Katter, M., Theil Kuhn, L., Bahl, C.R.H., Smith, A., Ancona-Torres, C. (2009). Characterization study of a plate of the magnetocaloric material $\mathrm{La}(\mathrm{Fe}, \mathrm{Co}, \mathrm{Si}) 13$. Proceedings of $3^{\text {rd }}$ International Conference on Magnetic Refrigeration at Room Temperature, IIF/IIR, p. 67-73. 